\title{
Earthquakes in Oita triggered by the 2016 M7.3 Kumamoto earthquake
}

Shingo Yoshida*

\begin{abstract}
During the passage of the seismic waves from the M7.3 Kumamoto, Kyushu, earthquake on April 16, 2016, a M5.7 [semiofficial value estimated by the Japan Meteorological Agency (JMA)] event occurred in the central part of Oita prefecture, approximately $80 \mathrm{~km}$ far away from the mainshock. Although there have been a number of reports that $M<5$ earthquakes were remotely triggered during the passage of seismic waves from mainshocks, there has been no evidence for $M>5$ triggered events. In this paper, we firstly confirm that this event is a M6-class event by reestimating the magnitude using the strong-motion records of K-NET and KiK-net, and crustal deformation data at the Yufuin station observed by the Geospatial Information Authority of Japan. Next, by investigating the aftershocks of 45 mainshocks which occurred over the past 20 years based on the JMA earthquake catalog (JMAEC), we found that the delay time of the 2016 M5.7 event in Oita was the shortest. Therefore, the M5.7 event could be regarded as an exceptional $M>5$ event that was triggered by passing seismic waves, unlike the usual triggered events and aftershocks. Moreover, a search of the JMAEC shows that in the 2016 Oita aftershock area, swarm earthquake activity was low over the past 30 years compared with neighboring areas. We also found that in the past, probably or possibly triggered events frequently occurred in the 2016 Oita aftershock area. The Oita area readily responds to remote triggering because of high geothermal activity and young volcanism in the area. The M5.7 Oita event was triggered by passing seismic waves, probably because large dynamic stress change was generated by the mainshock at a short distance and because the Oita area was already loaded to a critical stress state without a recent energy release as suggested by the past low swarm activity.
\end{abstract}

Keywords: Dynamic earthquake triggering, Aftershocks in Oita, The 2016 Kumamoto earthquake

\section{Introduction}

The M7.3 Kumamoto, Kyushu, Japan, earthquake at 01:25 on April 16, 2016, was accompanied by many aftershocks in Kumamoto and Oita prefectures (Fig. 1). Approximately $30 \mathrm{~s}$ after the $M 7.3$ mainshock which occurred in the Kumamoto area, a moderate event occurred in the Oita area during the passage of S waves from the M7.3 event. The Japan Meteorological Agency (JMA) estimated the magnitude of this event to be 5.7 , which is used as a semiofficial value because the seismic waves from the M7.3 event overlapped waves from the M5.7 event. Although the M5.7 event can be called an aftershock because of the relatively short distance from the

*Correspondence: shingo@eri.u-tokyo.ac.jp

Earthquake Research Institute, University of Tokyo, 1-1-1 Yayoi, Bunkyo-ku, Tokyo, Japan mainshock, this event has both the aspects of an aftershock and a dynamically triggered event since the Kumamoto aftershock area and the Oita aftershock area lie along different fault zones between which there is a seismic gap where almost no aftershocks occurred (Fig. 1d). The epicentral distance between the mainshock and the M5.7 event is approximately $80 \mathrm{~km}$.

Hill et al. (1993) studied seismicity remotely triggered by the 1992 M7.3 Landers earthquake. They found that triggered activities in two areas with at distances of 415 and $740 \mathrm{~km}$ from the mainshock began during the passage of surface waves from the $M 7.3$ event. The maximum magnitudes were 3.4 and 1.6, respectively, in the two areas. The largest earthquake triggered by the $M 7.3$ event was a M5.6 event in southern Nevada occurring $22 \mathrm{~h}$ after the mainshock at distance of $240 \mathrm{~km}$, which was preceded by smaller 19 events which started $91 \mathrm{~min}$ 


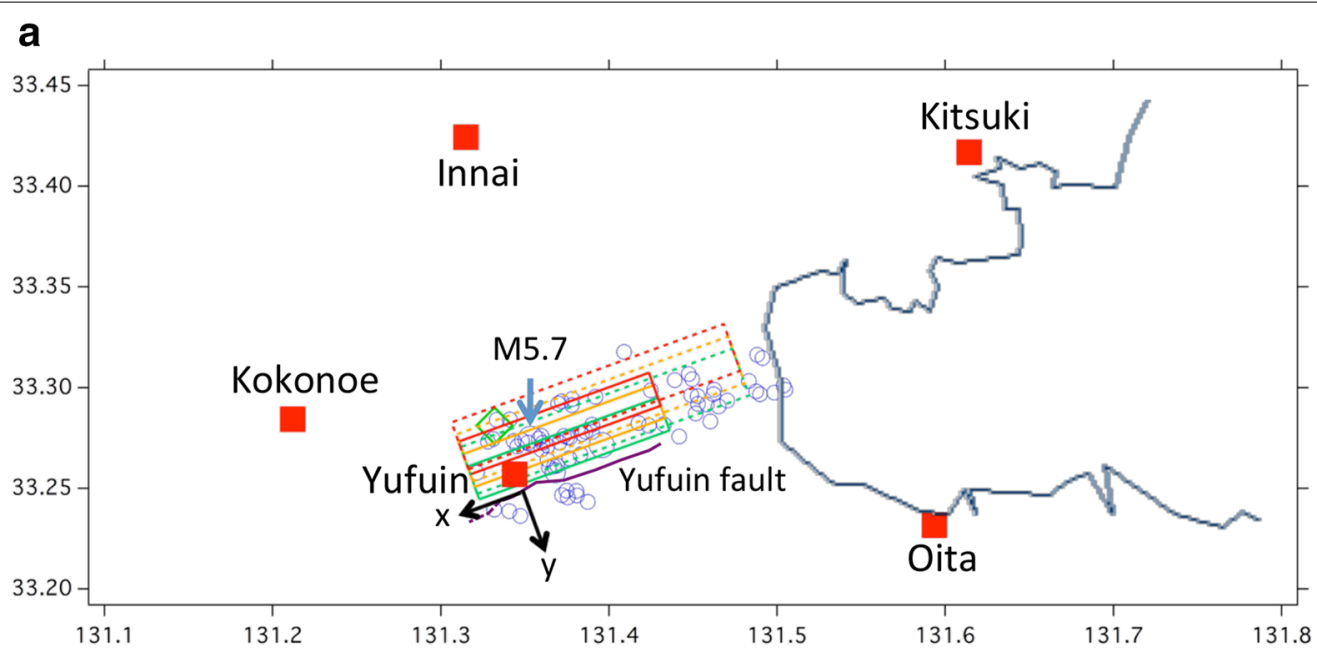

b

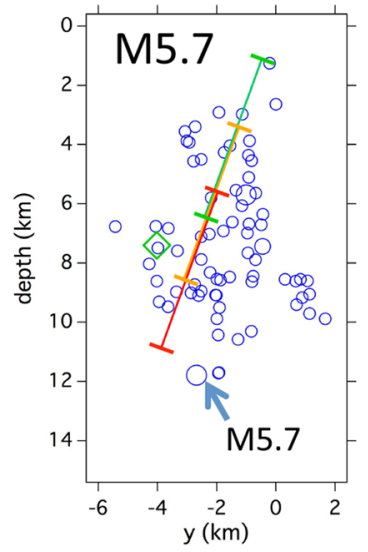

C

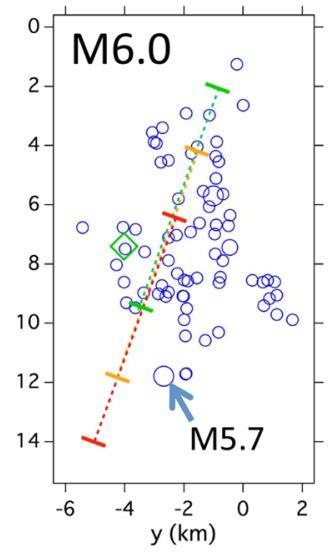

d

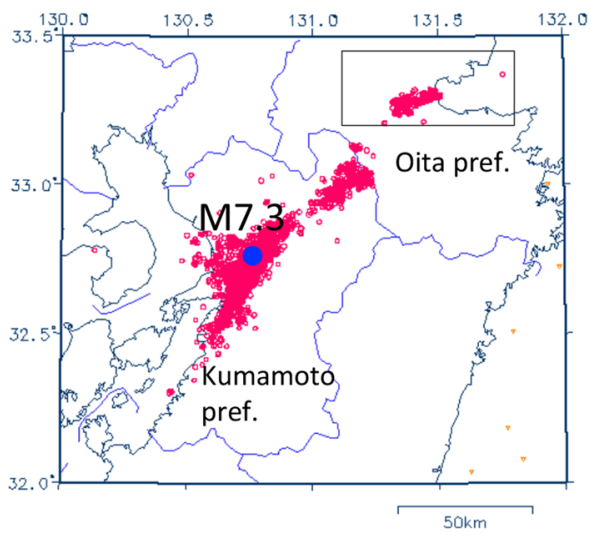

Fig. 1 a Epicenters of $M \geq 3$ aftershocks in the Oita area from April 16 to May 31, 2016, listed in the JMA earthquake catalog. The green diamond denotes the epicenters of the M5.7 event (semiofficial value by JMA) relocated in this study, which occurred immediately after the mainshock. The arrow indicates the hypocenter location of the M5.7 event determined by JMA. The red squares denote the K-NET and KiK-net stations used in this study. Assumed normal faults with a dip of $70^{\circ}$ for calculating surface displacements are also shown. For M5.7 models (solid line), $L=11.2 \mathrm{~km}$, $W=5.1 \mathrm{~km}$, and slip $=35.5 \mathrm{~cm}$. For $M 6.0$ models (dotted line), $L=16 \mathrm{~km}, W=8 \mathrm{~km}$, slip $=50 \mathrm{~cm}$. b Depth section of hypocenters and assumed $M$ 5.7 faults. The top and bottom depths are 5.4 and $10.6 \mathrm{~km}$ (red), 3.4 and $8.6 \mathrm{~km}$ (orange), and 1.4 and $6.6 \mathrm{~km}$ (green). c Assumed M6.0 faults with top and bottom depths of 6.2 and $13.8 \mathrm{~km}$ (red), 4.2 and $11.8 \mathrm{~km}$ (orange), and 2.2 and $9.8 \mathrm{~km}$ (green). d Epicenters of M 2 events from April 14 to May 31. The blue circle shows the M7.3 mainshock of April 16. The box denotes the area shown in a

after the mainshock. Yukutake et al. (2013) detected five earthquakes of $M \leq 4.2$ below the Hakone volcano during the passage of the surface waves from the 2011 M9.0 Tohoku-oki earthquake, whereas the largest event of $M 4.8$ occurred 22 min after. These studies imply that events triggered during surface waves have relatively small magnitudes $(M<5)$, whereas moderate events $(M \sim 5)$ occur several tens of minutes after the mainshock at the earliest. Parsons and Velasco (2011) found that there had been no significant increases in $5<M<7$ earthquake activity during the passage of surface waves from $205 M \geq 7$ mainshocks during the past 30 years.
The earliest onset of triggered $M>5$ events begins $\sim 200 \mathrm{~s}$ after the surface waves have passed, but most are delayed by hours. They considered that nucleation process for larger earthquakes requires a longer time.

If the semiofficial value of M5.7 is not an overestimation, the event in the Oita area can be considered to be an exceptional $M>5$ event that was triggered by passing seismic waves from the mainshock. In this paper, we firstly confirm whether M5.7 was an overestimation by using strong-ground-motion records and crustal deformation data. Next, using the JMA earthquake catalog (JMAEC), we investigate the delay times of aftershocks 
of 45 earthquakes which occurred in and around Japan to compare the delay time of the M5.7 event. Finally, we study swarm earthquake activities and the other triggered events in the Oita area.

\section{Estimation of magnitude}

As shown in Fig. 2, the acceleration records from the M5.7 event have much larger amplitudes than those from the mainshock, at the observation stations denoted in Fig. 1 of K-NET and KiK-net of the National Research Institute for Earth Science and Disaster Prevention (NIED). Integrating the acceleration records, we obtained the velocity data. The velocity waves from the M5.7 Oita event overlap the S coda waves from the M7.3 Kumamoto mainshock as shown in Fig. 2 (middle column). Applying a 1.5-Hz high-pass filter to the velocity records, we eliminated the overlapped mainshock coda waves, as shown in Fig. 2 (right hand). By reading the arrival times of the $\mathrm{P}$ and $\mathrm{S}$ waves, and the maximum amplitudes of the high-passed velocity, we located the event and estimated the magnitude. The located hypocenter was $33.28^{\circ} \mathrm{N}, 131.33^{\circ} \mathrm{E}$, depth $=7.4 \mathrm{~km}$, which is plotted in Fig. 1 as well as the epicenters of $M \geq 3$ aftershocks in the Oita area from April 16 to May 31, 2016, listed in the JMAEC. The location of this event determined by the JMA is $33.27^{\circ} \mathrm{N}, 131.35^{\circ} \mathrm{E}$, depth $=11.8 \mathrm{~km}$. Based on a formula proposed by Watanabe (1971), we estimated the magnitude to be 6.0 using the maximum velocities at the five stations.

Next, we examine the magnitude on the basis of crustal deformation. Figure 3 shows the vertical displacements during the $M 7.3$ event observed by the Geospatial Information Authority of Japan (GSI) (http://www.gsi.go.jp/ chibankansi/chikakukansi_kumamoto20160414.html). In the stations surrounding the Yufuin station, the vertical displacements are approximately zero, whereas a $5 \mathrm{~cm}$ subsidence is observed at the Yufuin station which is considered to be attributed to the M5.7 Oita event. The aftershocks in the Oita area are distributed along the Yufuin fault, as shown in Fig. 1. An active fault map (National Institute of Advanced Industrial Science and Technology 2016) shows that the Yufuin fault is a high-angle normal fault dipping northward. We calculated the vertical displacements using program code DC3D (NIED site, http:// www.bosai.go.jp/study/application/dc3d/DC3Dhtml_E. html) based on the formulation by Okada (1992) due to normal faults with a dip of $70^{\circ}$ assuming fault lengths $(L$ in $\mathrm{km})$, widths ( $W$ in $\mathrm{km})$, and slips $(D$ in $\mathrm{cm})$ corresponding to $M=5.7$ and 6.0 for various depths based on the following relations (Utsu et al. 1987): $\log L=0.5$ $M-1.8, \log D=0.5 M-1.3, L / W=2$. The assumed faults are shown in Fig. 1 with a caption denoting the top $\left(d_{1}\right)$ and bottom $\left(d_{2}\right)$ depths, $L, W$, and slip of the fault models.

Assuming $M=5.7$, the shallowest fault model over the depths from 1.4 to $6.6 \mathrm{~km}$ can account for a vertical displacement of approximately $5 \mathrm{~cm}$, although the depth of the M5.7 event was estimated by the JMA to be $11.8 \mathrm{~km}$. A fault model of $M 6.0$ can provide the observed displacements, and the depth $(7.4 \mathrm{~km})$ of this event estimated by this study falls within the range of the assumed fault.

Horizontal displacements observed by the GSI (http://www.gsi.go.jp/chibankansi/chikakukansi_kumamoto20160414.html) show a $4 \mathrm{~cm}$ right-lateral displacement along the Yufuin fault at Yufuin station. Since the observation stations surrounding the Yufuin station show some displacements, the displacement at Yufuin is affected also by the M7.3 mainshock. Figure 4 shows a right-lateral displacement of $1.5 \mathrm{~cm}$ for the shallow M6.0 fault model, which is consistent with the observation. When we assumed a normal fault with a strike-slip component, the horizontal displacement increased. Since the CMT solution (http://www.data.jma.go.jp/svd/eqev/ data/bulletin/cmt.html) estimated by the JMA of the M5.4 event which occurred near the M5.7 event at 07:11 on April 16 denotes a normal fault with a right-lateral slip component $(\mathrm{dip}=68$, strike $=243$, rake $=-148)$, the M5.7 event possibly has a strike-slip component. However, we cannot quantitatively constrain the strike-slip component from the data because we cannot separate the contributions from the M7.3 and M5.7 events.

From the estimations using strong-motion records and crustal deformation data, we can conclude that M5.7 is not overestimated. Since $M>5$ events are not usually triggered by passing seismic waves from respective mainshocks as described in "Introduction," this event in the Oita area can be considered to be an exceptional $M>5$ event. Because the event occurred during the passage of seismic waves, it is suggested that dynamic stress change played an important role. Miyazawa (2016) estimated the Coulomb failure stress change due to the passing waves of the M7.3 mainshock to be approximately $0.5 \mathrm{MPa}$ that is an order of magnitude larger than the estimated static stress change.

\section{Delay times of aftershocks}

In addition to the remote triggering reported by previous studies, in this subsection we focus on aftershocks to understand whether $M>5$ events can occur immediately after mainshocks, or during the passage of seismic waves from mainshocks including nearby cases. To address the problem, we investigate the delay times of aftershocks based on JMAEC using the search program TSEIS. Delay time here means the interval between a mainshock and an aftershock. 

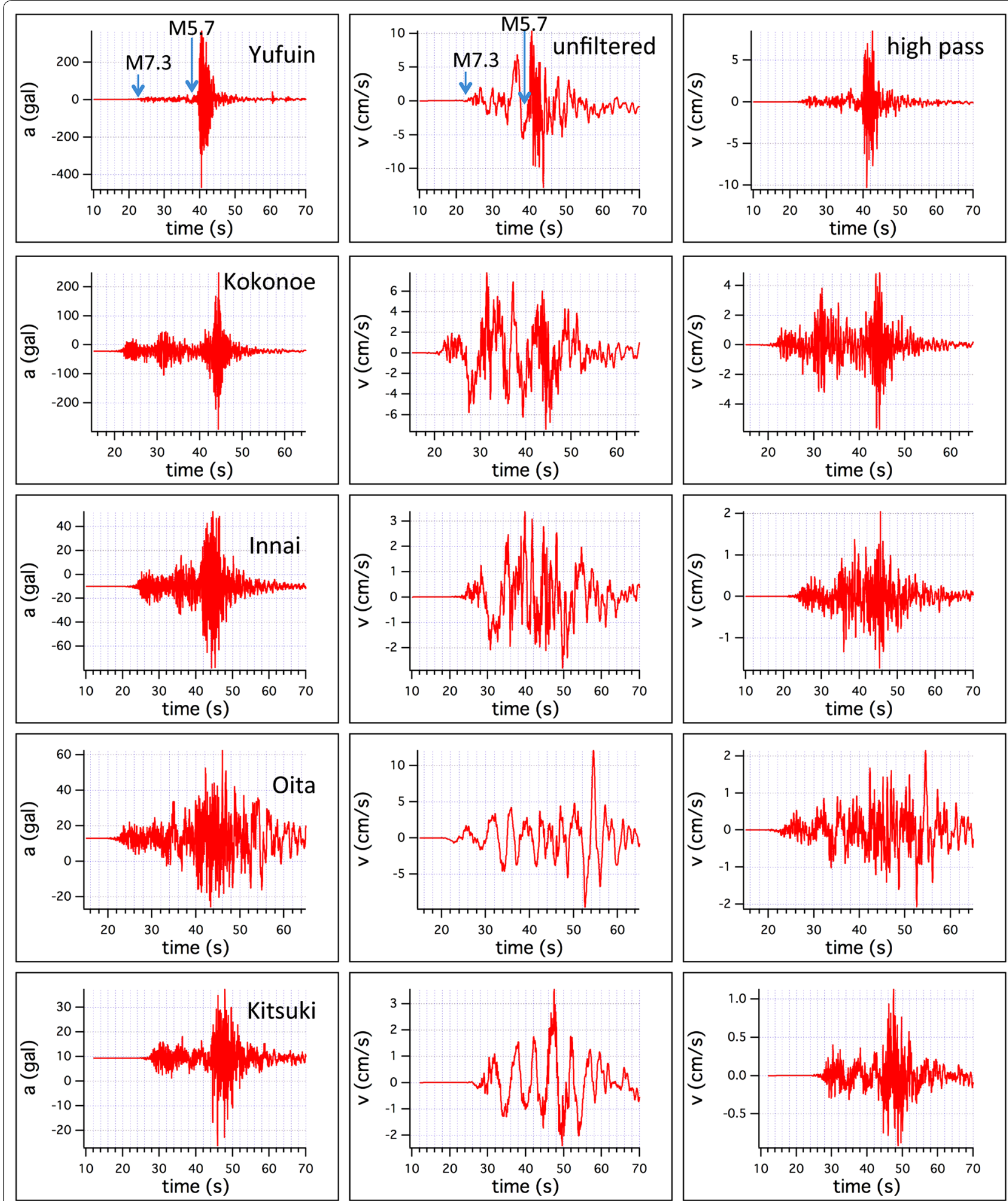

Fig. 2 Vertical component of acceleration (left), unfiltered velocity (middle), and 1.5-Hz high-pass filtered velocity (right) at five K-NET and KiK-net stations 


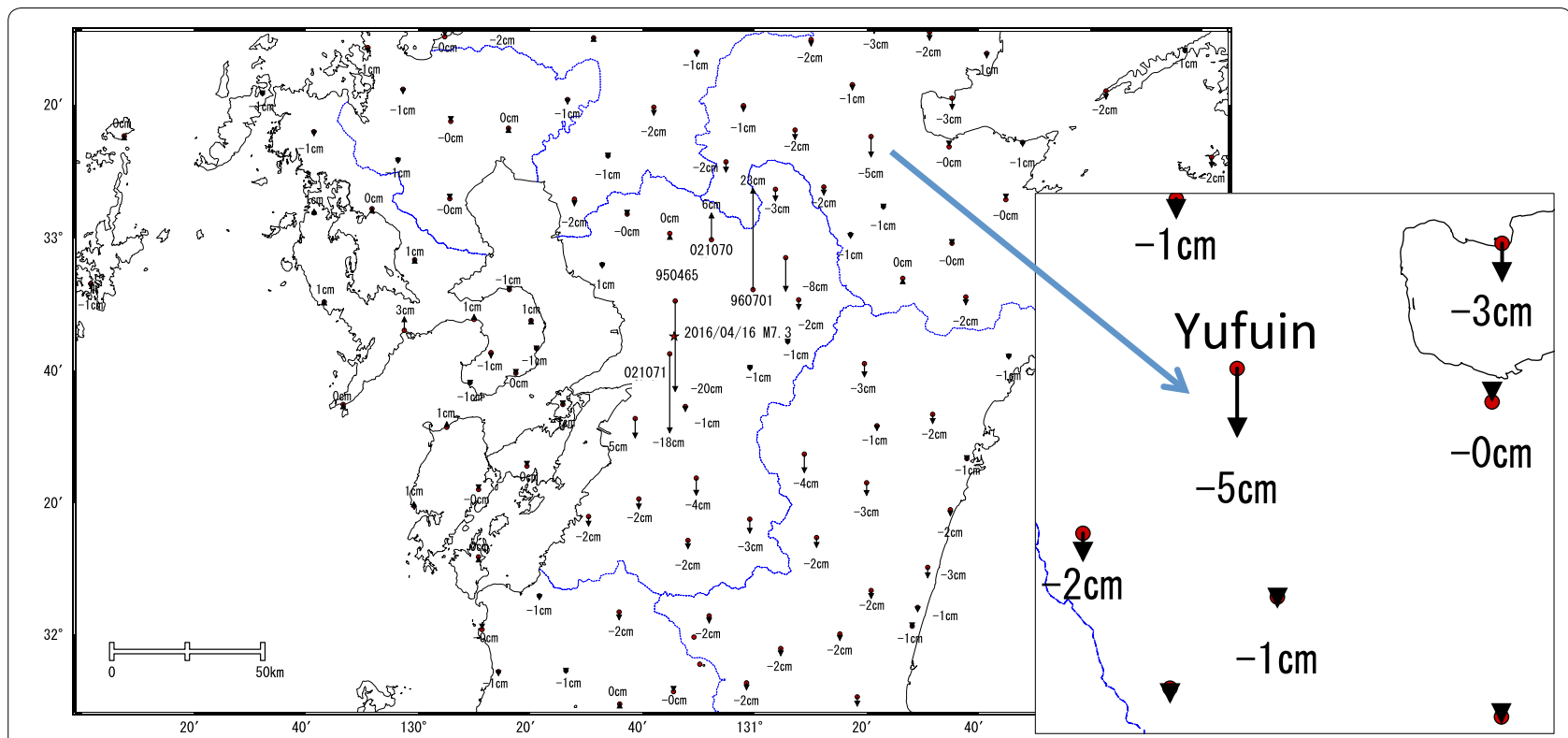

Fig. 3 Vertical displacements observed by the GSI. Inset shows a displacement of $5 \mathrm{~cm}$ subsidence at the Yufuin GPS station and its surrounding stations

Table 1 shows 45 earthquakes in and around Japan from 1995 to 2016 which were treated as mainshocks and whose data were analyzed in this study. $M \geq 6$ inland earthquakes, $M \geq 7$ offshore earthquakes, and some other events were chosen. Figure 5a shows the relation between the magnitudes and the delay times for the largest aftershock that occurred during the first month after each mainshock. The colors of the symbols denote the magnitudes of the mainshocks. When the M7.3 off Tohoku event on March 9, 2011, and the M6.5 Kumamoto event on April 14, 2016, were regarded as mainshocks, aftershocks were searched for during the first 2 days because each event was followed by a larger event (next mainshock) 2 days later. The shortest delay time was $0.12 \mathrm{~h}(7.2 \mathrm{~min})$ for a $M 4.9$ event after the 1997 M6.2 northwestern part of Kagoshima prefecture earthquake. Utsu (1961) studied the delay times of the largest aftershocks of 352 mainshocks which occurred from 1926 to 1959 . He found that the shortest delay time was $2 \mathrm{~min}$ for the event of M6.7 after the M7.0 Oga peninsula earthquake of May 1, 1939.

Figure $5 \mathrm{~b}$ shows the delay times for the earliest $M \geq 5$ aftershocks. The M5.7 Oita event after the 2016 Kumamoto earthquake shows the shortest delay time of $33 \mathrm{~s}$ $(0.009 \mathrm{~h})$. The second-shortest delay time is $1 \mathrm{~min} 36 \mathrm{~s}$ provided by the M5.7 event after the M7.0 Fukushima prefecture earthquake of April 11, 2011. As swarm earthquakes were triggered immediately after the 2011 Tohoku-oki earthquake in this area before the M7.0 mainshock, the sequence in the Fukushima area is not a typical mainshock-aftershock sequence. Nucleation process of the M5.7 event may have started before the M7.0 mainshock. The delay times of the earliest $M \geq 4$ aftershock and those of the earliest aftershocks of all magnitudes are shown in Fig. 5c, d. If a matched-filter technique (Shelly et al. 2007) is used, more events can be detected prior to the first event listed in the JMAEC. As far as the author knows, however, delay times shorter than that of the M5.7 Oita event have not been reported for $M \geq 5$ aftershocks. The largest aftershock of the 2016 Kumamoto earthquake was a M5.9 event. If we adopt M6.0 as the magnitude of the Oita event, as estimated in this paper, this event is plotted as the earliest event of the largest aftershock in Fig. 5a. The M5.7 Oita event is located far away from the mainshock compared with the other events of $M<8$ as shown in Fig. 5e.

Including remotely triggered events and aftershocks, no $M>5$ events have been known to occur immediately following mainshocks, or during the passage of seismic waves from respective mainshocks except in the case of the M5.7 Oita event. This M5.7 event may be an exceptional event triggered under particular conditions which we have not fully understood.

\section{Low earthquake swarm activities prior to the 2016 Kumamoto earthquake}

The red circles in Fig. $6 \mathrm{~b}$ show the epicenters of $M \geq 3$ earthquakes in the Oita area from 1983 to April 15, 2016, and Fig. $6 \mathrm{c}$ shows the cumulative number of earthquakes in the same period and area. Seismic swarm activities can be seen to have frequently occurred, each of which 
M5.7
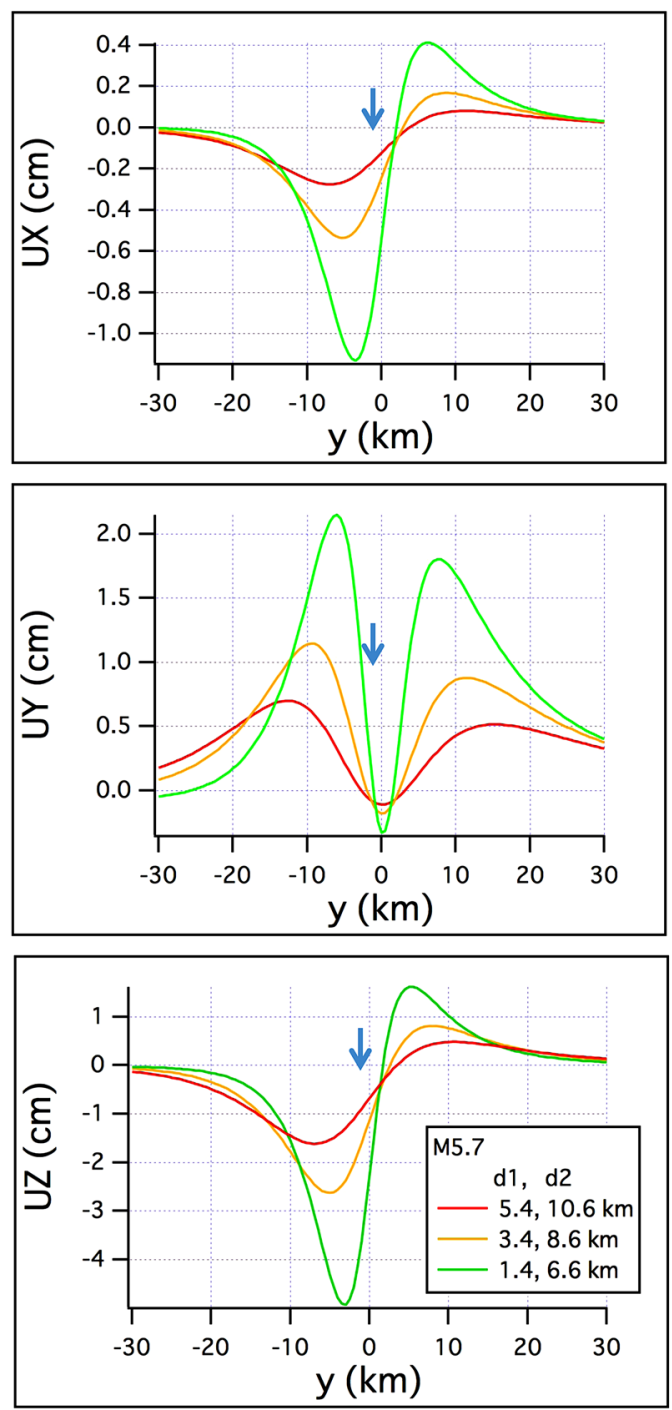

M6.0
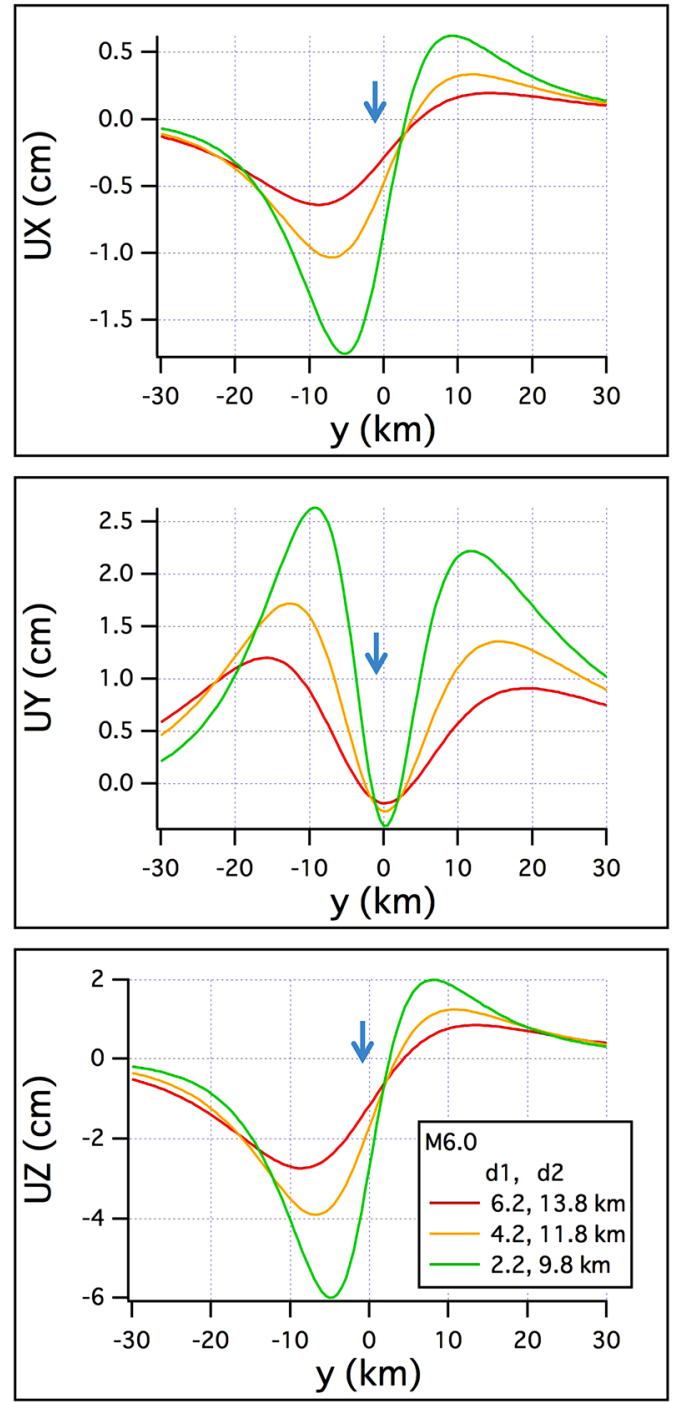

Fig. 4 Calculated displacements for various fault models of M5.7 (left) and M6.0 (right). $x, y$, and $z$ components are denoted from top to bottom. The arrows indicate the Yufuin GPS station

consisted of 100 to more than 1000 events. As the seismic swarms usually include $M \geq 3$ events, the areas shown in Fig. 6b, where $M \geq 3$ earthquakes occurred, are coincident with areas of swarm activities. The blue circles in Fig. 6b show $M \geq 3$ aftershocks from April 16 to May 31, 2016, for the 2016 Kumamoto earthquake, which are located along the Yufuin fault zone (the Yufuin fault and the extension section). It should be noted that the areas in which the $M \geq 3$ events occurred from 1982 up to the 2016 Kumamoto earthquake and the Yufuin fault zone where the 2016 aftershock occurred do not overlap each other. In other words, the 2016 aftershocks seem to have occurred in an area where there was low swarm activity for more than 30 years before the Kumamoto earthquake, although Fig. 6a shows that the distribution of $M \geq 2$ earthquakes from 1983 to April 15, 2016 (red), and the distribution of $M \geq 2$ aftershocks (blue) overlap in part.

After the 2011 M9.0 Tohoku-oki earthquake, inland events were triggered in many areas where seismic activities were relatively low before the $M 9.0$ event (e.g., Hashimoto 2011). These events are considered to have occurred as a result of a change in the static stress field. The aftershocks following the M5.7 Oita event in the Yufuin fault zone were probably caused by the combined effects of static stress change and delayed dynamically triggering due to both the M7.3 Kumamoto event and the M5.7 Oita event. The low swarm activity might have prohibited the Yufuin fault zone from large energy 
Table 1 Earthquakes for which aftershock delay times are examined

\begin{tabular}{|c|c|c|c|c|c|c|c|c|}
\hline \multirow[t]{2}{*}{ Date } & \multirow[t]{2}{*}{ Location } & \multirow{2}{*}{$\begin{array}{l}\text { Mainshock } \\
\text { M }\end{array}$} & \multicolumn{3}{|c|}{$\begin{array}{l}\text { The largest aftershock } \\
\text { The earliest } M \geq 5 \text { aftershock }\end{array}$} & \multicolumn{3}{|c|}{$\begin{array}{l}\text { The earliest } M \geq 4 \text { aftershock } \\
\text { The earliest aftershock }\end{array}$} \\
\hline & & & $M$ & Delay (h) & Distance (km) & $M$ & Delay (h) & Distance (km) \\
\hline \multirow[t]{2}{*}{ 07-01-1995 } & Off Iwate pref. & 7.2 & 6.2 & 3.975 & 11.7 & 4.0 & 0.127 & 3.9 \\
\hline & & & 6.2 & 3.975 & 11.7 & 4.0 & 0.127 & 3.9 \\
\hline \multirow[t]{2}{*}{ 17-01-1995 } & Kobe & 7.3 & 5.4 & 1.862 & 42.8 & 4.4 & 0.040 & 4.7 \\
\hline & & & 5.2 & 0.059 & 10.8 & 4.4 & 0.040 & 4.7 \\
\hline \multirow[t]{2}{*}{ 04-12-1995 } & SE off Etorofu & 7.3 & 6.7 & 0.224 & 52.9 & 6.1 & 0.158 & 36.9 \\
\hline & & & 6.1 & 0.158 & 36.9 & 6.1 & 0.158 & 36.9 \\
\hline \multirow[t]{2}{*}{ 26-03-1997 } & NW Kagoshima pref. & 6.6 & 4.9 & 0.121 & 1.7 & 4.9 & 0.121 & 1.7 \\
\hline & & & & & & 3.1 & 0.057 & 1.7 \\
\hline \multirow[t]{2}{*}{ 13-05-1997 } & Satsuma, Kyusyu & 6.4 & 5.1 & 17.894 & 4.2 & 5.1 & 17.894 & 4.2 \\
\hline & & & 5.1 & 17.894 & 4.2 & 2.8 & 0.131 & 8.5 \\
\hline \multirow[t]{2}{*}{ 25-06-1997 } & N Yamaguchi pref. & 6.6 & 4.3 & 6.743 & 0.4 & 4.0 & 0.136 & 3.4 \\
\hline & & & & & & 2.7 & 0.068 & 6.8 \\
\hline \multirow[t]{2}{*}{ 04-05-1998 } & SE off Ishigaki & 7.7 & 5.3 & 87.640 & 35.0 & 4.4 & 0.456 & 39.8 \\
\hline & & & 5.3 & 87.640 & 35.0 & 4.4 & 0.456 & 39.8 \\
\hline \multirow[t]{2}{*}{ 03-09-1998 } & N Iwate pref. & 6.2 & 4.3 & 0.201 & 5.4 & 4.3 & 0.201 & 5.4 \\
\hline & & & & & & 1.9 & 0.144 & 2.2 \\
\hline \multirow[t]{2}{*}{ 28-01-2000 } & SE off Nemuro Peninsula & 7.0 & 4.9 & 232.228 & 59.6 & 4.2 & 0.106 & 5.4 \\
\hline & & & & & & 3.7 & 0.088 & 5.8 \\
\hline \multirow[t]{2}{*}{$21-07-2000$} & Off Ibaraki pref. & 6.4 & 4.1 & 3.836 & 1.6 & 4.1 & 3.836 & 1.6 \\
\hline & & & & & & 2.6 & 0.103 & 3.5 \\
\hline \multirow[t]{2}{*}{$06-10-2000$} & WTotori pref. & 7.3 & 5.6 & 47.794 & 23.5 & 4.1 & 0.058 & 8.4 \\
\hline & & & 5.6 & 47.794 & 23.5 & 3.9 & 0.045 & 6.1 \\
\hline \multirow[t]{2}{*}{ 24-03-2001 } & Geiyo & 6.7 & 5.2 & 38.216 & 2.2 & 4.0 & 0.337 & 13.6 \\
\hline & & & 5.2 & 38.216 & 2.2 & 2.6 & 0.082 & 10.8 \\
\hline \multirow[t]{2}{*}{$18-12-2001$} & Near Yonagunijima & 7.3 & 5.7 & 236.645 & 14.3 & 4.4 & 0.124 & 11.3 \\
\hline & & & 5.0 & 0.734 & 10.6 & 4.4 & 0.124 & 11.3 \\
\hline \multirow[t]{2}{*}{ 26-03-2002 } & Near Ishigakijima & 7.0 & 5.3 & 3.100 & 22.7 & 5.3 & 3.100 & 22.7 \\
\hline & & & 5.3 & 3.100 & 22.7 & 2.5 & 0.797 & 25.6 \\
\hline \multirow[t]{2}{*}{$26-05-2003$} & Off Miyagi pref. & 7.1 & 4.9 & 357.992 & 12.3 & 4.1 & 0.070 & 2.9 \\
\hline & & & & & & 4.1 & 0.070 & 2.9 \\
\hline $26-07-2003$ & N Miyagi pref. & 6.4 & 5.5 & 9.720 & 10.7 & 4.0 & 0.025 & 4.2 \\
\hline & & & 5.1 & 3.148 & 5.7 & 4.0 & 0.025 & 4.2 \\
\hline $26-09-2003$ & Off Tokachi & 8.0 & 7.1 & 1.298 & 33.1 & 4.3 & 0.162 & 120.5 \\
\hline & & & 5.1 & 0.255 & 29.9 & 4.3 & 0.162 & 120.5 \\
\hline 05-09-2004 & SE off Kii Peninsula & 7.4 & 6.5 & 32.472 & 16.7 & 4.7 & 0.072 & 21.6 \\
\hline & & & 5.9 & 5.562 & 22.0 & 4.7 & 0.072 & 21.6 \\
\hline $23-10-2004$ & Chuetsu & 6.8 & 6.5 & 0.635 & 5.8 & 5.3 & 0.060 & 2.5 \\
\hline & & & 5.3 & 0.060 & 2.5 & 5.3 & 0.060 & 2.5 \\
\hline 29-11-2004 & Off Kushiro & 7.1 & 6.9 & 187.716 & 12.2 & 6.0 & 0.074 & 7.6 \\
\hline & & & 6.0 & 0.074 & 7.6 & 3.7 & 0.071 & 6.5 \\
\hline 20-03-2005 & W off Fukushima pref. & 7.0 & 5.8 & 739.296 & 12.4 & 4.6 & 0.037 & 6.9 \\
\hline & & & 5.4 & 53.031 & 1.5 & 4.6 & 0.037 & 6.9 \\
\hline 23-07-2005 & NW Chiba pref. & 6.0 & 4.7 & 344.508 & 3.3 & 4.6 & 0.041 & 2.9 \\
\hline & & & 4.6 & 0.041 & 2.9 & 4.6 & 0.041 & 2.9 \\
\hline $16-08-2005$ & Off Miyagi pref. & 7.2 & 4.7 & 640.702 & 8.2 & 4.6 & 0.094 & 11.6 \\
\hline & & & 4.6 & 0.094 & 11.6 & 3.1 & 0.087 & 30.2 \\
\hline $15-11-2005$ & Off Sanriku & 7.2 & 4.8 & 242.824 & 19.9 & 4.5 & 0.091 & 32.1 \\
\hline
\end{tabular}


Table 1 continued

\begin{tabular}{|c|c|c|c|c|c|c|c|c|}
\hline \multirow[t]{3}{*}{ Date } & \multirow[t]{3}{*}{ Location } & \multirow{3}{*}{$\begin{array}{l}\text { Mainshock } \\
\text { M }\end{array}$} & \multirow{2}{*}{\multicolumn{3}{|c|}{$\begin{array}{l}\text { The largest aftershock } \\
\text { The earliest } M \geq 5 \text { aftershock }\end{array}$}} & \multirow{2}{*}{\multicolumn{3}{|c|}{$\begin{array}{l}\text { The earliest } M \geq 4 \text { aftershock } \\
\text { The earliest aftershock }\end{array}$}} \\
\hline & & & & & & & & \\
\hline & & & $M$ & Delay (h) & Distance (km) & $M$ & Delay (h) & Distance (km) \\
\hline & & & & & & 4.5 & 0.091 & 32.1 \\
\hline \multirow[t]{2}{*}{ 25-03-2007 } & Off Noto Peninsula & 6.9 & 5.3 & 8.496 & 16.5 & 5.1 & 0.021 & 5.1 \\
\hline & & & 5.1 & 0.021 & 5.1 & 5.1 & 0.021 & 5.1 \\
\hline \multirow[t]{2}{*}{$16-07-2007$} & Off Chuetsu & 6.8 & 5.8 & 5.405 & 6.6 & 4.6 & 0.048 & 3.5 \\
\hline & & & 5.8 & 5.405 & 6.6 & 4.6 & 0.048 & 3.5 \\
\hline \multirow[t]{2}{*}{ 08-05-2008 } & Off Ibaraki pref. & 7.0 & 5.8 & 30.597 & 33.3 & 4.6 & 0.094 & 5.3 \\
\hline & & & 5.4 & 0.761 & 19.4 & 4.6 & 0.094 & 5.3 \\
\hline \multirow[t]{2}{*}{$14-06-2008$} & Iwate-Miyagi & 7.2 & 5.7 & 0.607 & 24.0 & 4.5 & 0.047 & 8.5 \\
\hline & & & 5.7 & 0.607 & 24.0 & 4.5 & 0.047 & 8.5 \\
\hline \multirow[t]{2}{*}{ 24-07-2008 } & Clwate pref. & 6.8 & 4.8 & 11.026 & 15.8 & 4.8 & 11.026 & 15.8 \\
\hline & & & & & & 2.7 & 0.234 & 2.9 \\
\hline \multirow[t]{2}{*}{ 11-09-2008 } & OffTokachi & 7.1 & 5.7 & 0.199 & 5.8 & 5.7 & 0.199 & 5.8 \\
\hline & & & 5.7 & 0.199 & 5.8 & 5.7 & 0.199 & 5.8 \\
\hline \multirow[t]{2}{*}{$11-08-2009$} & Suruga Bay & 6.5 & 4.5 & 61.066 & 10.1 & 4.0 & 1.102 & 14.1 \\
\hline & & & & & & 3.1 & 0.081 & 3.7 \\
\hline \multirow[t]{2}{*}{ 27-02-2010 } & Near Okinawa-honto & 7.2 & 5.4 & 15.807 & 0.4 & 4.0 & 0.242 & 12.1 \\
\hline & & & 5.1 & 4.288 & 4.1 & 3.1 & 0.151 & 11.1 \\
\hline \multirow[t]{2}{*}{$22-12-2010$} & Near Chichijima & 7.8 & 6.6 & 28.502 & 27.4 & 4.7 & 0.165 & 63.4 \\
\hline & & & 5.4 & 0.364 & 57.2 & 4.7 & 0.165 & 63.4 \\
\hline \multirow[t]{2}{*}{ 09-03-2011 } & OffTohoku & 7.3 & 6.8 & 18.646 & 26.9 & 4.6 & 0.148 & 27.0 \\
\hline & & & 6.2 & 0.199 & 10.30 & 4.6 & 0.148 & 27.0 \\
\hline \multirow[t]{2}{*}{$11-03-2011$} & OffTohoku & 9.0 & 7.6 & 0.488 & 262.4 & 6.8 & 0.084 & 103.8 \\
\hline & & & 6.8 & 0.084 & 103.8 & 6.8 & 0.084 & 103.8 \\
\hline \multirow[t]{2}{*}{$12-03-2011$} & N Nagano pref. & 6.7 & 5.9 & 0.544 & 4.7 & 4.1 & 0.073 & 7.3 \\
\hline & & & 5.9 & 0.544 & 4.7 & 3.6 & 0.033 & 7.6 \\
\hline \multirow[t]{2}{*}{ 15-03-2011 } & E Shizuoka pref. & 6.4 & 4.2 & 0.140 & 4.8 & 4.1 & 0.060 & 4.2 \\
\hline & & & & & & 3.2 & 0.035 & 3.0 \\
\hline \multirow[t]{2}{*}{ 07-04-2011 } & Off Miyagi pref. & 7.2 & 5.4 & 43.160 & 10.4 & 4.5 & 0.066 & 19.1 \\
\hline & & & 5.4 & 43.160 & 10.4 & 4.5 & 0.066 & 19.1 \\
\hline \multirow[t]{2}{*}{$11-04-2011$} & Fukushima Hamadori & 7.0 & 6.4 & 20.858 & 12.1 & 4.8 & 0.019 & 10.4 \\
\hline & & & 5.7 & 0.027 & 7.1 & 4.8 & 0.019 & 10.4 \\
\hline \multirow[t]{2}{*}{$07-12-2012$} & Off Sanriku & 7.3 & 6.6 & 0.211 & 11.1 & 4.1 & 0.183 & 30.2 \\
\hline & & & 6.6 & 0.211 & 11.14 & 3.3 & 0.170 & 32.5 \\
\hline \multirow[t]{2}{*}{$13-04-2013$} & Near Awajishima & 6.3 & 3.9 & 0.137 & 2.0 & & & \\
\hline & & & & & & 2.2 & 0.046 & 2.5 \\
\hline $22-11-2014$ & N Nagano pref. & 6.7 & 4.5 & 0.492 & 9.8 & 4.5 & 0.492 & 9.8 \\
\hline & & & & & & 3.4 & 0.034 & 5.0 \\
\hline $14-11-2015$ & W off Satsuma Peninsula & 7.1 & 5.9 & 22.480 & 44.6 & 5.2 & 0.431 & 9.8 \\
\hline & & & 5.2 & 0.431 & 9.8 & 3.5 & 0.157 & 37.2 \\
\hline 14-04-2016 & Kumamoto & 6.5 & 6.4 & 2.620 & 5.4 & 5.8 & 0.684 & 5.4 \\
\hline & & & 5.8 & 0.684 & 5.4 & 4.1 & 0.027 & 9.2 \\
\hline $16-04-2016$ & Kumamoto & 7.3 & 5.9 & 0.347 & 17.5 & 5.7 & 0.009 & 79.8 \\
\hline & & & 5.7 & 0.009 & 79.8 & 5.7 & 0.009 & 79.8 \\
\hline
\end{tabular}

The magnitudes, the delay times, and the distances from each mainshock are listed for the largest aftershock, the earliest $M>5$ aftershocks, the earliest $M \geq 4$ aftershocks, and the first aftershocks of all magnitudes. If the magnitude of the largest aftershock is $<5$, no data are filled for the earliest $M \geq 5$ aftershocks 

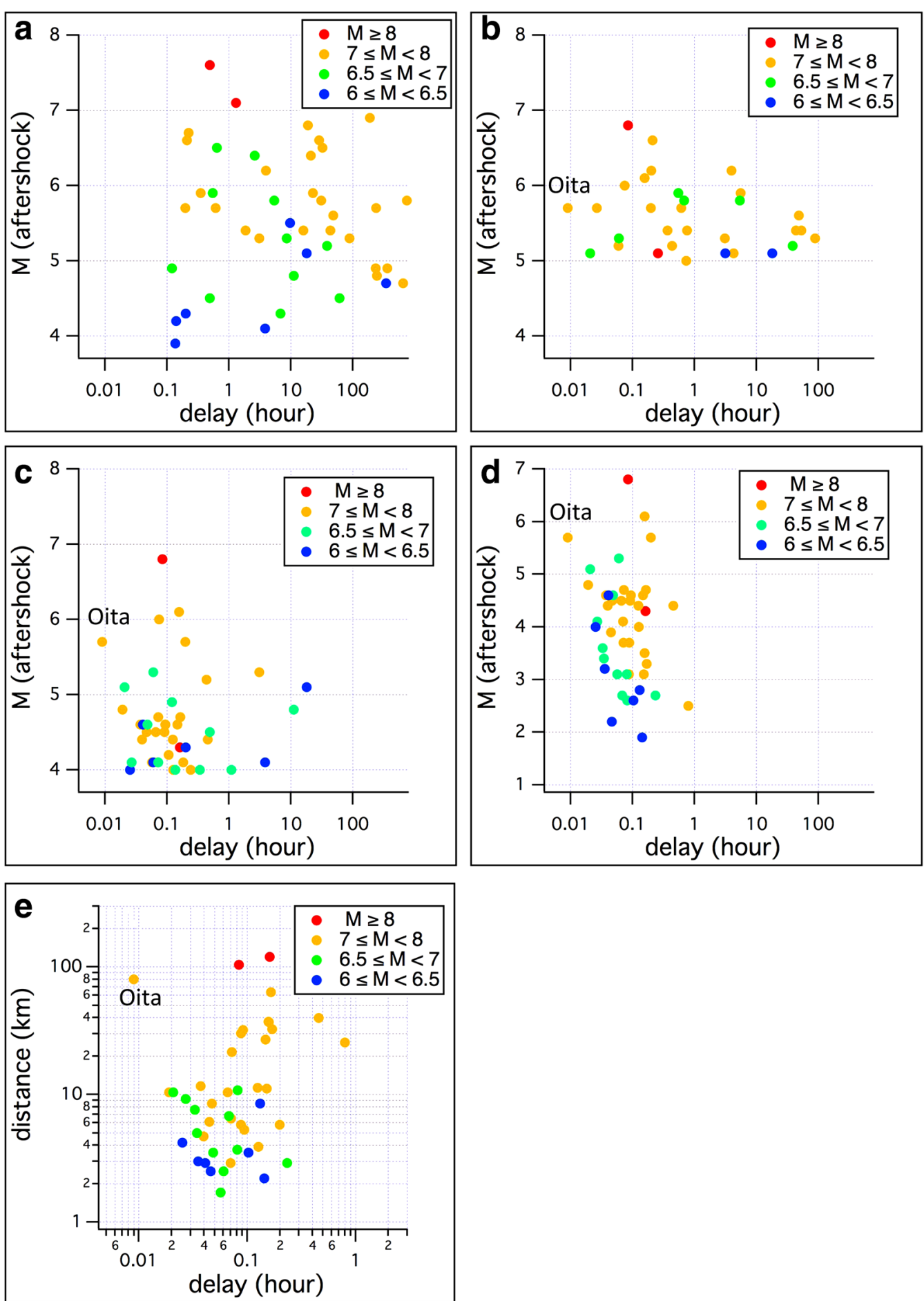

Fig. 5 Relations of the magnitudes of the aftershock and the delay time. a Largest aftershocks that occurred within 1 month after each mainshock. b Earliest $M \geq 5$ aftershocks. c Earliest $M \geq 4$ aftershocks. d Earliest aftershocks of all magnitudes. e Epicentral distances between the mainshock and the earliest aftershock versus the delay times 

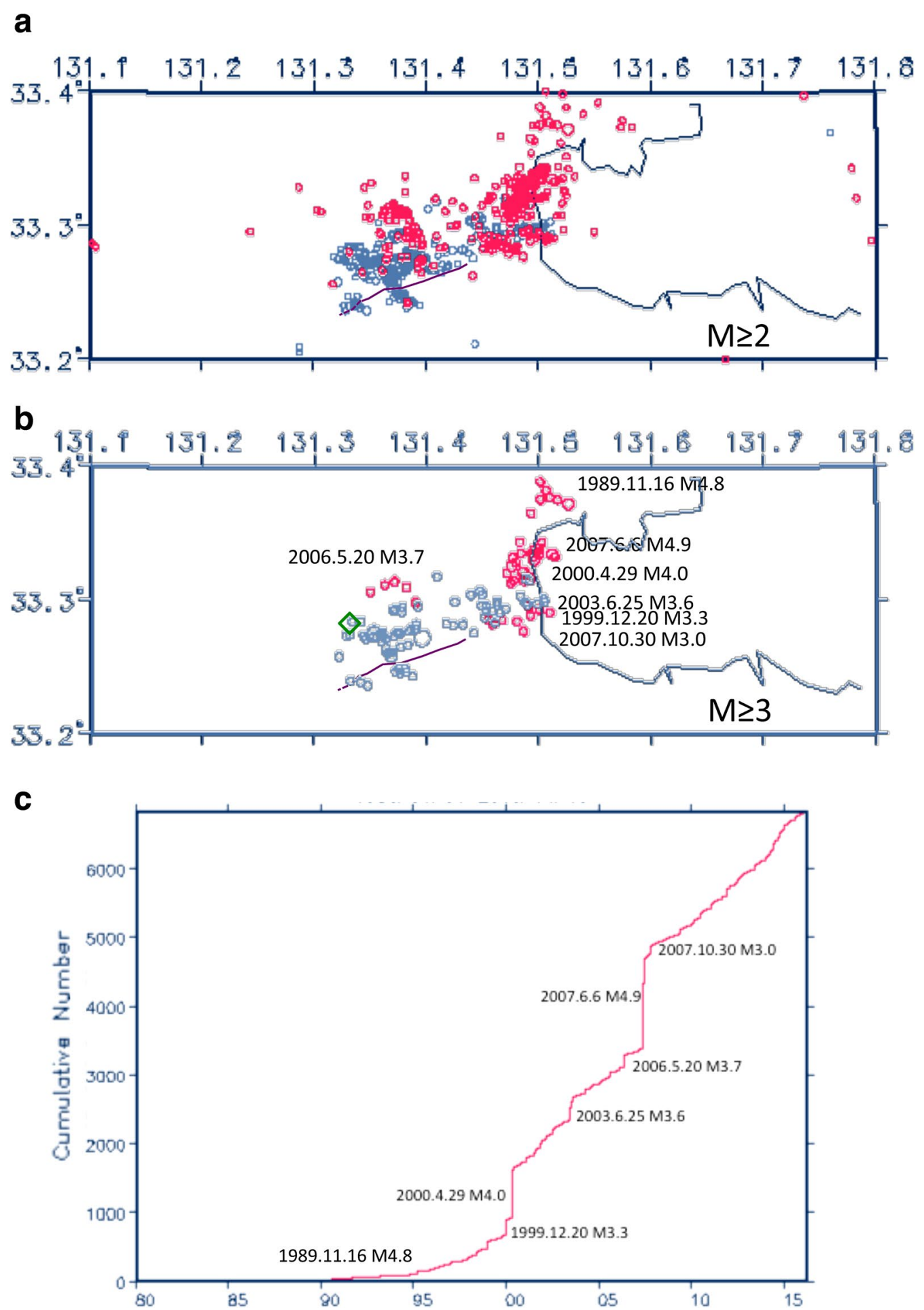

Fig. 6 Epicenters of $M \geq 2$ earthquakes from 1983 to April 15, 2016 (red), and $M \geq 2$ aftershocks from April 16 to May 31, 2016 (blue). b The same as a except for $M \geq 3$. The green diamond denotes the epicenter of the $M 5.7$ event relocated in this study. c Cumulative number of earthquakes of all magnitudes from 1983 to April 15, 2016 

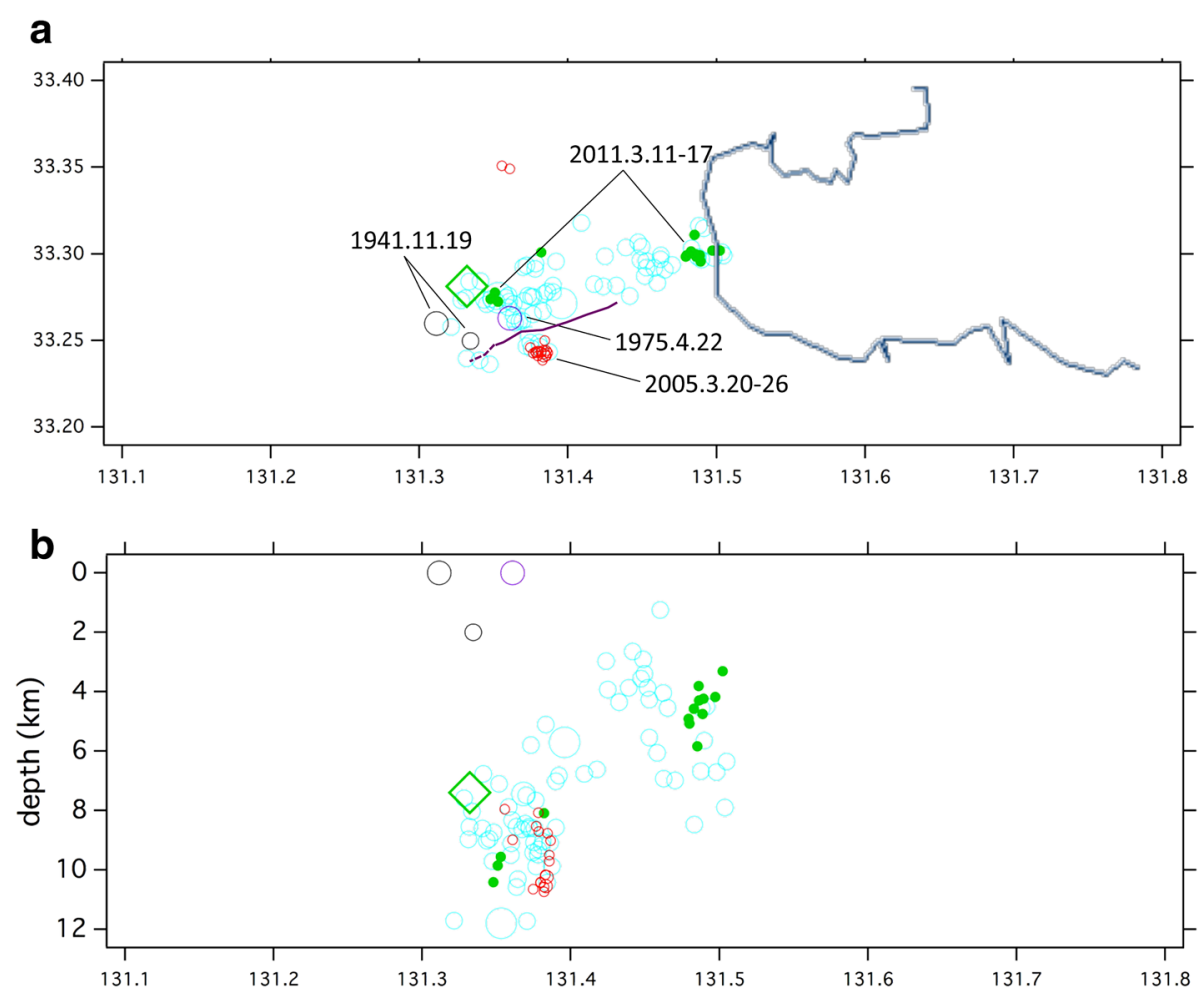

Fig. 7 Events possibly triggered by mainshocks. a The green circles show the events of all magnitudes during March 11-March 17, 2011, possibly triggered by the M9.0 Tohoku-oki earthquake. The red circles show the events of all magnitudes during the first week after the M7.2 West off Fukuoka prefecture earthquake of March 20, 2005. The purple circle shows the M4.1 event which occurred 1 day after the M6.4 central Oita earthquake of April 21, 1975. The gray circles denote the events which occurred on the same day of the M7.2 Hyuganada earthquake of November 19, 1941. The blue circles show epicenters of the 2016 M $\geq 3$ aftershocks. b Depth distributions. Those of 1975 and 1941 events have large errors. The green diamonds in $\mathbf{a}, \mathbf{b}$ denote the hypocenter of the M5.7 event relocated in this study

release, although $M \geq 2$ events frequently occurred before the Kumamoto event. In order to understand why the passing waves triggered the M5.7 event in a relatively inactive area, further investigation is needed.

\section{Other possibly triggered events in the Yufuin fault zone}

Miyazawa (2011) showed that many events were triggered during the passage of surface waves propagating over Japan in a southwestern direction from the 2011 M9.0 Tohoku-oki earthquake. Kiyomoto et al. (2014) obtained the earthquake distribution dynamically triggered during and immediately after the passage of the surface waves from the M9.0 event. Figure 4 in their paper shows that area of the triggered events in Oita is almost the same as the Yufuin fault zone. Green circles in Fig. 7 show $M \geq 0$ earthquakes that occurred in the Yufuin fault zone during the first week after the 2011 Tohoku-oki event listed in the JMAEC, which does not include the events detected by Kiyomoto et al. (2014). The cluster events that began 2 days after the M9.0 event are possibly triggered events. It is known that some swarm activities start as a result of delayed dynamic triggering and other swam activities start from a dynamically triggered event by passing waves and persist for certain period (e.g., Hill et al. 1993). As there was an interval of 2 days between the two cluster activities in the Oita case, the events shown in Fig. 7 could be classified as delayed triggered events, although such classification is not essential.

Figure 7 also shows that earthquake distribution (red) during the first week after the March 20, 2005, west off Fukuoka prefecture earthquake (M7.0) is concentrated within a small area $\left(131.37^{\circ} \mathrm{E}<\right.$ long. $<131.4^{\circ} \mathrm{E}$, $33.23^{\circ} \mathrm{N}<$ lat. $<33.26^{\circ} \mathrm{N}$ ) where the aftershock cluster of the 2016 Kumamoto earthquake is also concentrated. In the small confined area, 30 events occurred from 1983 to April 15, 2016, half of which occurred during the 3 days following the Fukuoka earthquake, and the other 15 events occurred sporadically over 30 years. This strongly suggests that the 15 events in 2005 were triggered by the Fukuoka earthquake. The 2016 aftershock distribution area along the Yufuin fault zone seems to be sensitive to dynamical triggering, whereas swarm activity was very low. 
Next, we examine the events that occurred during the earlier period, from 1923 to 1982 . The M4.1 event of April 22, 1975, shown in Fig. 7, is considered to be an aftershock or a triggered event due to the M6.4 central Oita earthquake of April 21, 1975. The other aftershocks of the M6.4 mainshock are distributed in the south of this area in the direction of WNW-ESE (Fig. 8), which is probably along the fault of the mainshock (e.g., Yamashina and Murai 1975). As the M4.1 event does not lie on this fault, this event was possibly triggered by the M6.4 mainshock, unlike typical usual aftershocks.

The M3.6 event at 15:35 and the M4.0 event at 19:54 on November 19, 1941, in Fig. 7 were probably triggered by the M7.2 Hyuganada, east off Kyusyu, earthquake at 01:46 of the same day. Figure 8 shows the epicenter of the M7.2 Hyuganada event and $M \geq 3$ events which occurred during the first week after the mainshock. In Hyuganada, other 4 $M \geq 7$ events have occurred since 1923 that did not trigger events in the Oita area. Although the earthquake activity in 1941 can be explained by non-causal coincidence, we cannot rule out the possibility that the $1941 M 7.2 \mathrm{Hyu}-$ ganada event triggered the two events which occurred on the same day in the Yufuin fault zone. Except the possibly triggered event, almost no $M \geq 3$ events occurred in the Yufuin fault zone from 1923 to 1982.

\section{Discussion and summary}

In the Yufuin fault zone, a M5.7 event was triggered during the passage of seismic waves from the 2016 Kumamoto earthquake. We confirmed that this event was a M6-class event by re-estimating the magnitude using the

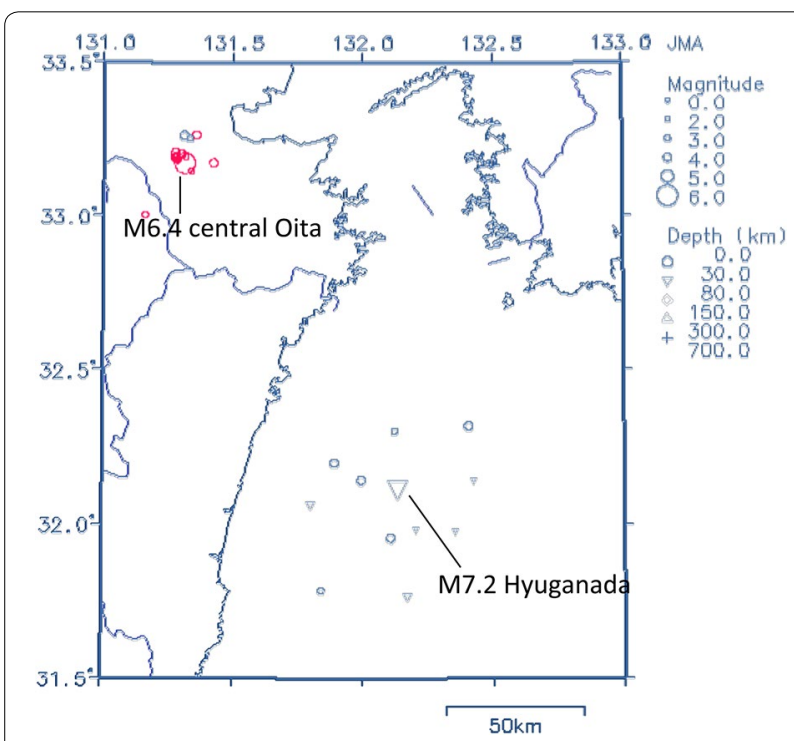

Fig. 8 Epicenters of the 1975 M6.4 central Oita earthquake (red), the 1941 M7.2 Hyuganada earthquake (blue), and $M \geq 3$ events which occurred during the first week following the mainshocks strong-motion records of K-NET and KiK-net, and crustal deformation data at the Yufuin station observed by the GSI. Previous studies have not reported that a $M>5$ event has ever been remotely triggered by passing seismic waves. We found that the delay time of the M5.7 Oita event is the shortest among the $M \geq 5$ aftershocks resulting from 45 mainshocks that recently occurred in and around Japan. Including remotely triggered events and aftershocks, no $M>5$ events have been known to occur immediately after a mainshock, or during the passage of seismic waves from a mainshock except in the case of the M5.7 Oita event. The M5.7 event could be regarded as an exceptional event.

In the 90 years prior to the 2016 Kumamoto earthquake, in the Yufuin fault zone no $M \geq 3$ earthquakes occurred, except for the possibly triggered events. This suggests that earthquake activity in this zone is relatively low during this period. On the other hand, the zone appears to respond readily to remote triggering by large earthquakes. Some events were triggered during the passage of the surface waves from the 2011 Tohokuoki earthquake. We found by searching the JMAEC that five mainshocks including the 2016 Kumamoto earthquake possibly triggered the events in the Yufuin fault zone. Hill et al. (1993) pointed out that many sites of remotely triggered activity are closely associated with areas of geothermal activity or young volcanism. Oita prefecture is the most geothermally active area in Japan, and young volcanoes, Yufudake and Tsurumidake, exist along the Yufuin fault zone. The Yufuin zone has both conditions for triggered activity. Hill et al. (1993) also pointed out that one of the significant factors for remote triggering is nonlinear interaction between dynamic stress in seismic waves and crustal fluids. Parsons (2005) argued that it is possible that the seismic waves could change some of the frictional parameters leading to a triggered event. Nagata et al. (2012) introduced shear stress effect to the rate- and state-dependent frictional law, suggesting that dynamic stress change could cause change in the contact state of a fault surface. Whether events are triggered during the passage of the seismic waves or delayed triggered is probably determined by combined effects depending on respective conditions. Harris and Day (1993) performed numerical simulations of rupture propagation along parallel strike-slip faults to investigate a jump over a fault step including the cases taking account of effects of pore pressure changes. Although their assumed geometry was different from the fault zones in Kumamoto and Oita, extended simulations would be helpful for understanding the cause of dynamic trigger in Oita area, where hydrothermal effects probably played an important role. 
The M5.7 Oita event was triggered by passing seismic waves probably because a large dynamic stress change was generated by the mainshock at a short distance and because the Yufuin fault zone was already loaded to a critical stress state without recent large energy release. The latter is suggested by the low swarm activity in the Yufuin fault zone before the 2016 Kumamoto earthquake.

\section{Acknowledgements}

We thank M. Savege and two anonymous reviewers for insightful reviews. I used the TSEIS visualization package (Tsuruoka 1998) for searching the hypocenter data.

\section{Competing interests}

The author declares that he has no competing interests.

Received: 31 July 2016 Accepted: 26 October 2016

Published online: 14 November 2016

\section{References}

Harris RA, Day SM (1993) Dynamics of fault interaction: parallel strike-slip faults. J Geophys Res 98:4461-4472

Hashimoto M (2011) The 2011 Tohoku-oki earthquake: mainshock and triggered event. J JSNDS 30-1:27-38 (in Japanese)

Hill DP, Reasenberg PA, Michael A, Arabaz WJ, Beroza G, Brumbaugh D, Brune JN, Castro R, Davis S, dePolo D, Ellsworth WL, Gomberg J, Harmsen S, House L, Jackson SM, Johnston MJS, Jones L, Keller R, Malone S, Munguia L, Nava S, Pechmann JC, Sanford A, Simpson RW, Smith RB, Stark M, Stickney M, Vidal A, Walter S, Wong V, Zollweg J (1993) Seismicity remotely triggered by the magnitude 7.3 Landers, California, earthquake. Science 260:1617-1623. doi:10.1126/science.260.5114.1617

Kiyomoto M, Moriwaki K, Suganuma I, Tamaribuchi K, Nagaoka Y (2014) The earthquake distribution of the dynamic triggering from the 2011 off the Pacific Coast of Tohoku earthquake. Q J Seismol 77:323-327 (in Japanese)
Miyazawa M (2011) Propagation of an earthquake triggering front from the 2011 Tohoku-Oki earthquake. Geophys Res Lett 38:L23307. doi:10.1029/ 2011 GL049795

Miyazawa M (2016) Triggered significant seismicity in Oita following the M7.3 Kumamoto earthquake in 2016. Japan Geoscience Union Meeting 2016, abstract MIS34-P10

Nagata K, Nakatani M, Yoshida S (2012) A revised rate- and state-dependent friction law obtained by constraining constitutive and evolution laws separately with laboratory data. J Geophys Res 117:B02314. doi:10.1029/ $2011 \mathrm{JB} 008818$

National Institute of Advanced Industrial Science and Technology (2016) Active fault database of Japan. https://gbank.gsj.jp/activefault/index_e_ gmap.html

Okada Y (1992) Internal deformation due to shear and tensile faults in a halfspace. Bull Seismol Soc Am 82:1018-1040

Parsons T (2005) A hypothesis for delayed dynamic earthquake triggering. Geophys Res Lett. doi:10.1029/2004GL021811

Parsons T, Velasco AA (2011) Absence of remotely triggered large earthquakes beyond the mainshock region. Nat Geosci 4:316-321. doi:10.1038/ ngeo 1110

Shelly DR, Beroza GC, Ide S (2007) Non-volcanic tremor and low-frequency earthquake swarms. Nature 446:305. doi:10.1038/nature05666

Tsuruoka H (1998) Development of seismicity analysis software on workstation, vol 2. Tech. res. rep. ERI, University of Tokyo, pp 34-42 (in Japanese)

Utsu T (1961) A statistical study on the occurrence of aftershocks. Geophys Mag 30:521-605

Utsu T, Shima E, Yoshii T, Yamashina K (eds) (1987) Encyclopedia of earthquakes, 2nd edn. Asakura, Tokyo

Watanabe $H$ (1971) Determination of earthquake magnitude at regional distance in and near Japan. Zisin 24:189-200 (in Japanese)

Yamashina K, Murai I (1975) On the focal mechanisms of the earthquakes in the central part of Oita prefecture and in the northern part of Aso of 1975, especially, the relations to the active fault system. Bull Earthq Res Inst 50:295-302 (in Japanese)

Yukutake Y, Miyazawa M, Honda R, Harada M, Ito H, Sakaue M, Koketsu K, Yoshida A (2013) Remotely triggered seismic activity in Hakone volcano during and after the passage of surface waves from the 2011 M9.0 Tohoku-Oki earthquake. Earth Planet Sci Lett 373:205-216. doi:10.1016/j. epsl.2013.05.004

\section{Submit your manuscript to a SpringerOpen ${ }^{\circ}$ journal and benefit from:}

- Convenient online submission

- Rigorous peer review

- Immediate publication on acceptance

- Open access: articles freely available online

- High visibility within the field

- Retaining the copyright to your article

Submit your next manuscript at $\boldsymbol{\nabla}$ springeropen.com 